\title{
Study of Silent Coronary Artery Disease in Type 2 Diabetics by Stress Test
}

\author{
Authors \\ Dr Nuvvula Siva Krishna*, Dr Anu Gaikwad, Dr S.A. Kanitkar, \\ Dr Vaja Mukhtar Ahmed, Dr Sura Sreekar, Dr Dumpala Rajneesh Reddy, \\ Dr George Thomson Ben \\ Department of General Medicine Dr. D. Y. Patil Medical College, Hospital And Research Centre, \\ PIMPRI, Pune \\ *Corresponding Author \\ Dr Nuvvula Siva Krishna \\ A2- 804 Manikbaug Orchid, Nehrunagar, PIMPRI, Pune-411018, India
}

\begin{abstract}
Background: Coronary heart disease is the common impact of death worldwide in DM and $10 \%$ of the population attributable risk of a first MI.4 In today's world, most of the deaths are attributable to noncommunicable disease and just over half of these are as a result of IHD. In India, the situation is no different from other part of the world. Diabetes can cause autonomic neuropathy which can blunt any pain alert mechanism contributing towards higher incidence of painless myocardial infarctions in diabetes.

Methods: 100 patients with Diabetes Mellitus according to American Diabetes Association criteria, who are willing to participate in our study age more 20 years and less than 80 years attending OPD or admitted in Department of General Medicine Dr. D. Y. Patil medical college, hospital and research centre, pimpri, pune during the study period from May 2017 to April 2020.

Results: Out of 100 cases 53 were males 47 were females the positive stress test for ishemic heart disease was observed in 28 patients out of them 14 were males and 14 were females. there was statistically significance $(p<0.05)$ in mean values of BSL $(F \& P P 1), H b A 1 C$, total cholesterol, triglyceride and LDL for stress test positive and negative groups.

Conclusions: Increase in HbAlc levels, dyslipidaemia and elevated blood glucose levels were associated significantly with incidence of silent MI in patients with type 2 diabetes. It is recommended that control of sugars is necessary for prevention of coronary artery disease.

Keywords: Diabetes Mellitus, Coronary Artery Disease, Stress Test.
\end{abstract}

\section{Introduction}

Diabetes Mellitus (DM) is hyperglycemia due to defect in insulin secretion or insulin resistance. ${ }^{1}$ World health organization (WHO) reports show that 69.2 million people had diabetes in the year 2015 and nearly 98 million people in India may have type 2 diabetes by $2030^{1}$. Diabetes and cardiovascular diseases are rapidly gaining pandemic proportions in south East Asian subcontinent, and India is leading the race ${ }^{1}$. Hyperglycaemia decreases endothelium-derived Nitric Oxide availability and affects vascular function mainly through the increased production of Reactive Oxygen Species. It can cause progressive tissue damage and both micro and macro vascular complications. At present DM and 
its complications are on rise in both developed and developing countries. ${ }^{2}$ Leading cause of mortality in DM is ischemic heart disease. Ischemic heart disease is often asymptomatic in diabetic patients until onset of myocardial infarction or sudden cardiac death. ${ }^{3}$ According to WHO India leads the world with largest number of diabetic subjects earning the dubious distinction of being termed the "diabetes capital of the world". 5 Coronary heart disease is the common impact of death worldwide in DM and $10 \%$ of the population attributable risk of a first MI. ${ }^{4}$ In today's world, most of the deaths are attributable to non-communicable disease and just over half of these are as a result of IHD. In India, the situation is no different from other part of the world. Diabetes can cause autonomic neuropathy which can blunt any pain alert mechanism contributing towards higher incidence of painless myocardial infarctions among the persons suffering from diabetes. American Diabetes Association (ADA) recommends that all patients with diabetes and either a family history of coronary artery disease or cardio-vascular risk factors should be screened using a tread mill test (TMT) or a coronary artery angiography. ${ }^{6}$ The screening for early myocardial ischemia helps in preventing worsening of the cardiac disease especially in high risk groups who had family history of cardiovascular deaths.

\section{Methodology}

100 patients with Diabetes Mellitus according to American Diabetes Association (ADA) criteria, who are willing to participate in our study age more 20 years and less than 80 years attending OPD or admitted in Department of General Medicine Dr. D. Y. Patil medical college, hospital and research centre, pimpri, pune during the study period from May 2017 to April 2020.

\section{Inclusion Criteria}

1) Patients who were known Diabetic.

2) Patients who has no symptoms of IHD.

3) Patients with age between 20- 80 years.

\section{Exclusion Criteria}

1) Patients who have symptoms of IHD like chest pain, breathlessness and dyspnea on exertion and known IHD patients.

2) Patients who have other systemic disorders like Liver, Renal diseases and cerebro vascular attack patients.

\section{Procedure}

\section{Stress Test}

The patient was explained about the procedure not to take caffeinated beverages before three hours of TMT and to wear loose clothes and shoes. A brief general examination was done before the TMT and consent was taken. A standard ECG was taken following which a torso ECG was taken in the lying down and in the standing or sitting position. BP was taken in both positions and the patient was explained on how to perform the test. Standard multistage maximal exercise test was done on a motorized treadmill according to Bruce protocol. The heart rate, BP and ECGs were taken after each stage of exercise, immediately before and after stopping the exercise and for each minute for at least five to ten minutes in the recovery phase. TMT was terminated in all patients following the achievement of target heart rate or an abnormal ischemic response. This was defined as development of $0.10 \mathrm{mV}(1 \mathrm{~mm})$ of $\mathrm{J}$ point depression measured from the PQ junction, with a relatively flat ST segment slope $(<1 \mathrm{mV} / \mathrm{sec})$, depressed $\geq 0.10 \mathrm{mV} 60$ to $80 \mathrm{msec}$ after the $\mathrm{J}$ point in three consecutive beats with a stable baseline. Exercise test was also terminated if patient had chest pain, dyspnoea or fatigue.

\section{Lab Investigations}

Hemoglobin, TLC, Platelet count, LFTs, RFTs, BSL Fasting and Post prandial, Fasting Lipid Profile, HbA1C. Trop-T, CPK-MB.

\section{Statistical Analysis}

Data analysis was done using Microsoft excel sheet. Tables and graphs were prepared for the variables. Pearson chi-square test was used for 


\section{JMSCR Vol||07||Issue||11||Page 835-840||November}

categorical variables in the study. In our study $\mathrm{P}$ value which was less than 0.05 was considered as significant. The continuous variables were assessed using students T test.

\section{Results}

In our study out of 100 cases 53 were males 47 were females the positive stress test for ischemic heart disease was observed in 28 patients out of them 14 were males and 14 were females.

Table: TMT Findings among Study Subjects

\begin{tabular}{|l|c|c|}
\hline TMT & Frequency & Percent \\
\hline Negative & 72 & 72.0 \\
\hline Positive & 28 & 28.0 \\
\hline Total & 100 & 100.0 \\
\hline
\end{tabular}

Above table shows TMT findings among Study Subjects.

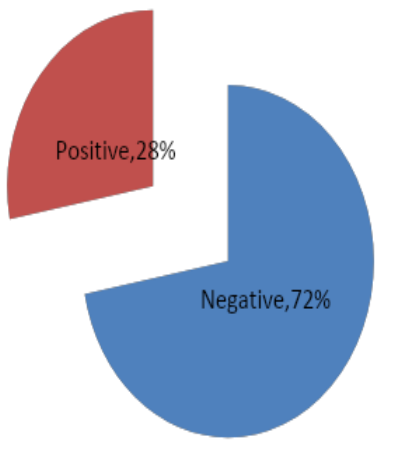

Graph: TMT Findings among Study Subjects.

Table: Relation of TMT with Gender

\begin{tabular}{|l|c|c|c|c|}
\hline \multirow{2}{*}{$\begin{array}{l}\text { Gende } \\
\text { r }\end{array}$} & \multicolumn{2}{|c|}{ TMT } & \multirow{2}{*}{ Total } & $\begin{array}{c}\text { P } \\
\text { Value }\end{array}$ \\
\cline { 2 - 3 } & Negative & Positive & & \multirow{2}{*}{0.708} \\
\hline Female & $33(70.2 \%)$ & $14(29.8 \%)$ & 47 & \\
\hline Male & $39(73.6 \%)$ & $14(26.4 \%)$ & 53 & \\
\hline Total & 72 & 28 & 100 & \\
\hline
\end{tabular}

Table shows relation of TMT with Gender. It was found that there was no significant

Difference in trade mill test findings across gender $(\mathrm{p}>0.05)$

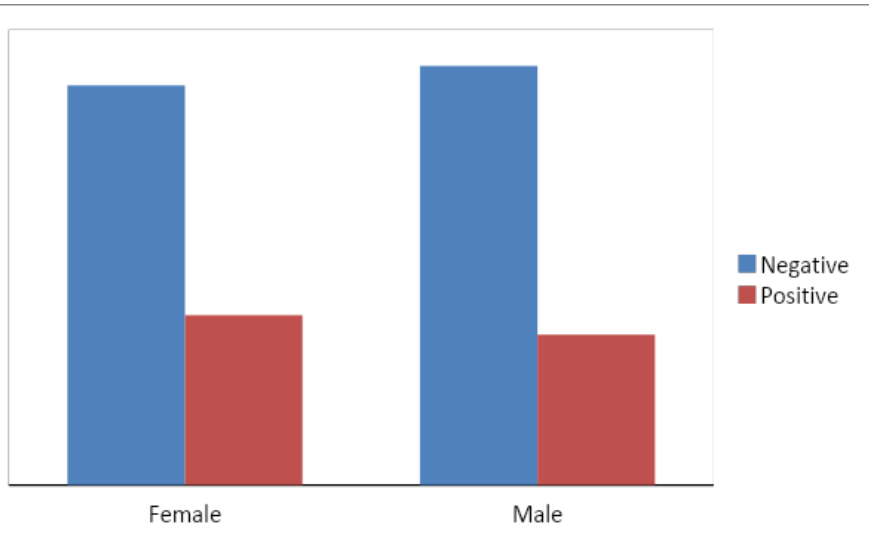

Graph: Relation of TMT with Gender

Table: Correlation of continuous variables with trade mill test findings

\begin{tabular}{|c|c|c|c|}
\hline \multirow{2}{*}{$\begin{array}{c}\text { Variables } \\
\text { Age }\end{array}$} & \multicolumn{2}{|c|}{ Trade Mill } & \\
\cline { 2 - 4 } & Positive & Negative & P Value \\
\cline { 2 - 4 } & $52.93+8.9$ & $52.94+9.6$ & 0.994 \\
\hline $\begin{array}{c}\text { Duration of } \\
\text { DM }\end{array}$ & $9.96+5.3$ & $8.64+5.2$ & 0.265 \\
\hline BSL-F & $191.25+46.19$ & $166.56+37.83$ & $\mathbf{0 . 0 0 7}$ \\
\hline BSL-PP & $243.14+48.62$ & $222.57+48.577$ & $\mathbf{0 . 0 0 6}$ \\
\hline HbA1C & $10.65+2.64$ & $8.94+2.1$ & $\mathbf{0 . 0 0 1}$ \\
\hline Total & $224.75+34.9$ & $176.61+25.4$ & $\mathbf{0 . 0 0 0 1}$ \\
\hline Cholesterol & $160.96+30.8$ & $125.58+28.6$ & $\mathbf{0 . 0 0 0 1}$ \\
\hline Triglyceride & $107.54+29.1$ & $87.53+25.16$ & $\mathbf{0 . 0 0 1}$ \\
\hline LDL & $58.03+30.28$ & $56.86+27.5$ & 0.853 \\
\hline HDL & $32.57+12.6$ & $34.21+14.6$ & 0.604 \\
\hline VLDL & \multicolumn{2}{|c|}{. } \\
\hline
\end{tabular}

Table shows correlation between different continuous variables with trade mill test findings. Except for age, HDL and VLDL there was statistically significance $(p<0.05)$ in mean values of BSL (F\&PP1), HbA1C, total cholesterol, triglyceride and LDL for test positive and negative groups.

Table: Relation of Coronary angiography findings with TMT

\begin{tabular}{|l|c|c|c|c|}
\hline \multirow{2}{*}{ TMT } & \multicolumn{2}{|c|}{ CAG Disease status } & & \multirow{2}{*}{ P value } \\
\cline { 2 - 4 } & Present & Absent & Total & \\
\hline Positive & $18(81.8 \%)$ & $4(18.2 \%)$ & 22 & \multirow{2}{*}{0.0001} \\
\hline $\begin{array}{l}\text { Negativ } \\
\text { e }\end{array}$ & 0 & $\begin{array}{c}78 \\
(100 \%)\end{array}$ & 78 & \\
\hline Total & 18 & 82 & 100 & \\
\hline
\end{tabular}

Table shows relation of Coronary angiography findings with TMT. Out of 22 TMT positive subjects $18(81.8 \%)$ showed coronary artery disease on coronary angiography. There was significant difference in presence of coronary disease status in relation to TMT result $(\mathrm{p}<0.05)$ 


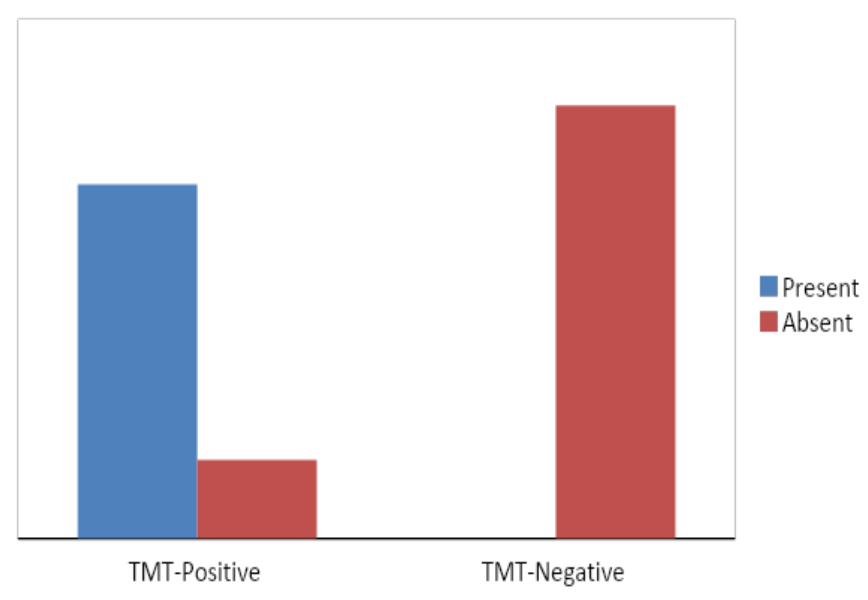

Graph: Relation of Coronary angiography findings with TMT

\section{Discussion}

Coronary Artery Disease detection in DM patients without any symptoms is often delayed. The preponderance of SMI in DM is variable and ranges from 9 to $75 \% .^{7}$

In this study out of 100 cases 53 were males 47 were females the positive TMT was observed in 28 patients out of them 14 were males and 14 were females. Our findings were similar to previous studies. Falcone $\mathrm{C}$ et al study ${ }^{8}$ found that $29 \%$ diabetics that had no symptoms for CAD had SMI on exercise electrocardiogram.

Sukhija R et al study $^{9}$ showed that increased prevalence of SMI in DM as compared to nondiabetics. Sargin $\mathrm{H}$ et al study showed that $38.3 \%$ of DM beyond prior CAD had SMI on TMT. Quek DK et al ${ }^{11}$ identified that 113 patients out of 522 patients $(22 \%)$ had SMI using TMT in asymptomatic type $2 \mathrm{DM}$ patients. The results were similar to the prevalence recorded by Swaminathan and Gayathri in their study which showed that TMT was positive in $30 \%(n=15){ }^{12}$ Anurag S Lavekar et al study Out of 161 patients, $34(21.1 \%)$ patients were positive stress test, while 90 patients were negative stress test $(55.9 \%)$ and $37(22.9 \%)$ were inconclusive for IHD based on stress test. Our study showed that DM patients had higher chances of silent MI. Diabetes is one of the strong risk factor for IHD but in present study there is no statistical significance in sex distribution regarding IHD.

\section{Duration of DM AND IHD}

In present study we found that there was no statistical significance between duration of DM and IHD with a $\mathrm{p}$ value 0.265.Gupta SB et $\mathrm{al}^{7}$ studied over 500 patients with type 2 DM with normal basic ECG found that, 62(12.4\%) patients had IHD on TMT. The positive TMT was associated with longer duration of DM $(\mathrm{p}<0.005)$.

\section{HbA1C and IHD}

The increased levels of glycosylated hemoglobin indicated poor glycemic control and it has great influence on CAD. In our study we found that average $\mathrm{HbA1C}(\%)$ in Treadmill test positive and negative cases were 10.65 and 8.94 respectively. Statistically significant value of $\mathrm{p}(0.001)$ was found in $\mathrm{HbA1C}(\%)$ levels between both the groups.

Valensi $\mathrm{P}$ study ${ }^{10}$, it showed that with increasing HbA1c levels there was increase in the coronary vessels involvement with $\mathrm{CAD}(\mathrm{p}<0.0001)$.

Dyslipidemia and IHD In the present study, we found that the average total cholesterol levels in TMT positive patients were $224.75 \mathrm{mg} / \mathrm{dl}$ and in negative $176.61 \mathrm{mg} / \mathrm{dl}$. Average triglyceride in subjects TMT positive was $160.96 \mathrm{mg} / \mathrm{dl}$ and negative cases and $125.58 \mathrm{mg} / \mathrm{dl}$. Average LDL was $107.54 \mathrm{mg} \%$ in TMT positive cases and 87.53 $\mathrm{mg} \%$ in negative cases. Average HDL was 58.03 $\mathrm{mg} \%$ in TMT positive cases and $56.86 \mathrm{mg} \%$ in negative cases. Statistically significant values of $\mathrm{p}$ $=0.0001, \mathrm{p}=0.001, \mathrm{p}=0.0001$ was found in LDL, triglyceride and Total cholesterol levels between both the groups. Lehto et al ${ }^{13}$ studied in 1059 subjects and found that patients with a high serum cholesterol level had 2 fold increase in the risk of CHD. Mathura $\mathrm{KC}$ et al study found that abnormality in lipids was common in DM and the most commonly increased serum triglyceride levels $(73.3 \%)$ The next was decreased serum HDL and LDL levels. Both seen in $66.7 \%$. Coronary artery disease had a stronger correlation with high levels of triglycerides. Panagiotakos et $\mathrm{al}^{14}$ (2003) conducted a case-control study 
performed on 272 patients and found that the LDL/HDL ratio was an important risk factor of cardiovascular disease in DM patients and that a LDL/HDL cholesterol ratio more than 8 was associated with a $66 \%$ increases the risk of CAD.

\section{Coronary Angiography in Type 2 Diabetes Mellitus}

In our study we found that total 28 patients were positive for TMT, out of them CAG was performed for 22 patients, 18 patients had CAD and 4 patients had normal CAG.

Goraya et al found that IHD nearly $3 / 4$ th of individuals with DM who did not have any clinical symptoms IHD; > 50\% of asymptomatic subjects had multi vessel disease. Hence, DM is considered to be a "CHD equivalent".

\section{Conclusion}

The study clearly showed that the prevalence of silent MI was higher among the type 2 diabetic individuals. Increase in HbAlc levels, dyslipidaemia and elevated blood glucose levels were associated significantly with incidence of silent MI in patients with type 2 diabetes. It is recommended that control of sugars is necessary for prevention of coronary artery disease. It is highly recommended to screen every high-risk patient with type 2 diabetes with TMT once a year to prevent loss of life to cardio-vascular mortality. TMT \& subsequent CAG in TMT positive patient is the right approach considering the cost benefit ratio of all asymptomatic patients and necessary revascularization before multi vessel involvement and multiple organ failure.

\section{Abbreviations}

DM-Diabetes Mellitus, WHO- World health organization, MI-Myocardial Infarction, IHDIschemic Heart Disease, ADA- American Diabetes Association, TMT- Thread Mill Test, ECG-Elecrocardiogram, TLC-Total Leucocyte Count, HbA1C-Glycated Hemoglobin, BSLBlood Sugar Level, PP-Post Prandial, LDL-Low Density Lipoproteins HDL-High Density
Lipoproteins, VLDL-Very Low Density Lipoproteins, CAD-Coronary Artery Disease, CHD-Coronary Heart Disease, CAG-Coronary Angiography, SMI-Silent Myocardial Infarction.

\section{References}

1. Mathers CD, Loncar D. Projections of global mortality and burden of disease from 2002 to 2030. PLoS medicine. 2006 Nov 28;3(11):e442

2. Alexander CM, Landsman PB, Teutsch SM. Diabetes mellitus, impaired fasting glucose, atherosclerotic risk factors, and prevalence of coronary heart disease. The American journal of cardiology. $2000 \mathrm{Nov}$ 1;86(9):897-902.

3. Rajagopalan N, Miller TD, Hodge DO, Frye RL, Gibbons RJ. Identifying highrisk asymptomatic diabetic patients who are candidates for screening stress singlephoton emission computed tomography imaging. Journal of the American College of Cardiology. 2005 Jan 4;45(1):43-9.

4. Giagnoni E, Secchi MB, Wu SC, Morabito A, Oltrona L, Mancarella S, Volpin N, Fossa L, Bettazzi L, Arangio G, Sachero A. Prognostic value of exercise EKG testing in asymptomatic normotensive subjects: a prospective matched study. New England Journal of Medicine. 1983 Nov 3;309(18):1085-9

5. Mohan V, Sandeep S, Deepa R, Shah B, Varghese C. Epidemiology of type 2 diabetes: Indian scenario. The Indian journal of medical research. 2007 Mar 1;125(3):217-30.

6. Warst A, Wang PS, LaValley MP, Avorn J, Solomon DH. American Diabetes Association Clinical Practice Recommendations Diabetes Care: 1 (S1) 12. Self management education program in chronic disease: a systematic revue and methodological critique of the literature. Arch Intern Med. 2004;164:1641-9. 
7. Gupta SB, Pandit RB. Silent myocardial ischaemia and cardiac autonomic neuropathy in diabetics. Indian heart journal. 1992;44(4):227-9.

8. Falcone C, Nespoli L, Geroldi D, Gazzaruso C, Buzzi MP, Auguadro C, Tavazzi L, Schwartz PJ. Silent myocardial ischemia in diabetic and nondiabetic patients with coronary artery disease. International journal of cardiology. 2003 Aug 1;90(2-3):219-27.

9. Sukhija R, Dhanwal D, Gambhir DS, Dewan R. Silent myocardial ischaemia in patients with type II diabetes mellitus and its relation with autonomic dysfunction. Indian heart journal. 2000;52(5):540-6.

10. Valensi P, Sachs RN, Harfouche B, Lormeau B, Paries J, Cosson E, Paycha F, Leutenegger M, Attali JR. Predictive value of cardiac autonomic neuropathy in diabetic patients with or without silent myocardial ischemia. Diabetes care. 2001 Feb 1;24(2):339-43.

11. Quek DK, Khor PG, Ong SB. Association of diabetic autonomic neuropathy with painless myocardial ischaemia induced by exercise. Singapore medical journal. 1992 Apr;33(2):177-81.

12. Swaminathan DK, Gayathri DM. "Study of treadmill test in detecting asymptomatic coronary artery disease in type 2 diabetes mellitus." IOSR J Dental Medi Sci. 2016;15(08):1-6.

13. Lehto S, Rönnemaa T, Haffher SM, Pyörälä K, Kallio V, Laakso M. Dyslipidemia and hyperglycemia predict coronary heart disease events in middleaged patients with NIDDM. Diabetes. 1997 Aug 1;46(8):1354-9.
14. Pourmoghaddas A, POUR MOGHADAS M, Sanei H. Evaluation of Waist-Hip Ratio in Patients with Coronary Artery Disease. Iranian Heart Journal. 2001 Mar 1;2(2.3):32-6. 